\title{
A Case of Inoperable Duodenal Cancer Achieving Long-Term Survival after Multidisciplinary Treatment
}

\author{
Takashi Ando $^{\mathrm{a}}$ Takeshi Ishikawa $^{\mathrm{b}}$ Eiko Imamoto $^{\mathrm{a}}$ \\ Etsuko Kishimoto ${ }^{a}$ Kentaro Suzuki $^{c}$ Yutaka Isozaki ${ }^{c}$ \\ Naoyuki Matsumoto ${ }^{c}$ Hirokazu Oyamada ${ }^{c}$ \\ Tsuguhiro Matsumoto $^{b}$ Kazuhiko Uchiyama $^{\mathrm{b}}$ \\ Osamu Handa ${ }^{b}$ Tomohisa Takagi $^{b}$ Nobuaki Yagi ${ }^{b}$ \\ Satoshi Kokura ${ }^{b}$ Yuji Naito $^{b}$ Toshikazu Yoshikawa $^{b}$ \\ ${ }^{a}$ Department of Gastroenterology, Social Insurance Kyoto Hospital, and \\ ${ }^{b}$ Department of Gastroenterology, Kyoto Prefectural University of Medicine, \\ Kyoto, and 'Department of Gastroenterology, Matsushita Memorial Hospital, \\ Moriguchi, Japan
}

\section{Key Words}

Duodenal cancer $\cdot$ Chemotherapy $\cdot$ S- $1 \cdot$ Multidisciplinary treatment

\begin{abstract}
A 50-year-old female became aware of skin yellowing and consulted another hospital where she was diagnosed intraoperatively with duodenal cancer because of lymph node metastases around the aorta. Endoscopy revealed type lla + IIc cancer distal to the duodenal papilla, and biopsy allowed a diagnosis of well-differentiated adenocarcinoma. Computed tomography revealed a large number of lymph node metastases around the aorta and in the left supraclavicular cavity. The patient was given many regimens of chemotherapy, mainly containing S-1, and multidisciplinary treatment, and achieved long-term survival for 6 years and 1 month. This is a valuable case suggesting the usefulness of this therapeutic approach. In view of the fact that duodenal cancer is a relatively rare disease and the possibility that the incidence of this disease may increase in the future, it seems essential to collect additional data from multicenter prospective studies towards the goal of establishing a standard method of treatment for this disease.
\end{abstract}




\section{Introduction}

Duodenal cancer was previously viewed as a rare type of cancer. Because of the rarity of this cancer, there are few reports on chemotherapy for duodenal cancer. The 5 -year survival rate of duodenal cancer is reported to be less than $30 \%[1,2]$. On the other hand, it is reported that resection improves 5-year survival. When the tumor is resectable, pancreatoduodenostomy is the most common operative procedure, as the majority of tumors originate in the periampullary region.

Although cases of duodenal cancer treated with relatively noninvasive methods such as endoscopic treatment have been reported, the usefulness of chemotherapy has been reported to be low in cases of inoperable duodenal cancer, and no standard method of treatment has been established for this type of duodenal cancer. However, the establishment of a standard treatment is important because reports on this cancer have recently been increasing following improvement in the diagnosis using procedures such as computed tomography (CT), magnetic resonance imaging and endoscopy including endoscopic ultrasonography, capsule endoscopy and double balloon endoscopy.

S-1 is an oral anti-cancer agent, composed of tegafur, 5-chloro-2,4-dihydroxypyridine, and potassium oxonate, at a molar ratio of 1:0.4:1 [3]. It is based on the biochemical modulation of 5-fluorouracil and reported to be effective in patients with advanced gastrocolorectal cancer [4-6]. We recently encountered a case of inoperable duodenal cancer where long-term survival for 6 years and 1 month was achieved by multidisciplinary treatment such as the chemotherapy mainly using S-1.

\section{Case Report}

A 50-year-old female became aware of skin yellowing and consulted another hospital where she was diagnosed intraoperatively with duodenal cancer in December 2001 because of lymph node metastases around the aorta. A catheter for endoscopic nasal biliary drainage was left inserted, and the patient was referred to our hospital. Two lymph nodes, each about $1 \mathrm{~cm}$ in diameter, were palpable in the left supraclavicular cavity, but no other noteworthy abnormality was found. In the laboratory data on admission, mild liver dysfunction with jaundice was recognized and carcinoembryonic antigen (CEA) was $4,987 \mathrm{ng} / \mathrm{ml}$. Endoscopy revealed early-stage cancer (IIa + IIc) distal to the duodenal papilla (fig. 1a), and biopsy allowed a diagnosis of well-differentiated adenocarcinoma (fig. 1b). CT revealed a large number of lymph node metastases around the aorta and in the left supraclavicular cavity (fig. 1c, d). Endoscopic retrograde cholangiopancreatography revealed no stenosis or dilation of common or intrahepatic bile duct. Wall irregularities were also absent. On the basis of these findings, this case was rated as inoperable also at our hospital, and chemotherapy was administered.

In January 2002, the patient began to receive S-1/cisplatin (CDDP) therapy resembling a regimen used for gastric cancer. After the start of treatment, the primary lesion disappeared and lymph node metastases also markedly decreased in size (fig. $2 \mathrm{a}, \mathrm{b}$ ). CEA normalized at the end of the $10^{\text {th }}$ course of treatment (fig. 3). Later numbness, a known adverse reaction to CDDP, developed. In January 2003, the therapy was switched to S-1/irinotecan (CPT-11) therapy. In December 2003, the patient was rated as showing complete response on the basis of findings from 2-deoxy-18F-fluoro-glucose positron emission tomography (FDG-PET) and CT (fig. 2c, d). The treatment was then switched to uncombined S-1 therapy. Thereafter no recurrence was noted and the regimen was switched to consecutive-day UFT therapy in February 2005.

In September 2005, swelling of lymph nodes in the left supraclavicular cavity was noted, and a judgment of tumor recurrence in the lymph nodes was made. The regimen was therefore switched to 
$\mathrm{S}-1 / \mathrm{CPT}-11$. However, the response rate was progressive disease by CT, and CEA rose to $24.7 \mathrm{ng} / \mathrm{ml}$. This therapy was therefore discontinued after the second cycle. In December 2005, weekly paclitaxel (PTX) therapy was started, but lymph node swelling of the left supraclavicular cavity intensified and the therapy was switched in February 2006 to weekly docetaxel therapy with radiotherapy. The response rated by $\mathrm{CT}$ after this therapy was complete response.

In July 2006, CEA rose again and the regimen was switched to uncombined S-1 therapy. In the same month, multiple brain metastases were detected, and gamma knife therapy of the same area was additionally applied. Later, tumor recurrence and onset of new lesion were noted, and gamma knife therapy was additionally performed in February and October 2007.

In January 2007, FDG-PET revealed metastasis to the right axillary lymph nodes. At that time, regional lymph node excision was performed at the department of surgery, followed by radiotherapy ( $50 \mathrm{~Gy}$ in total) of the same area. In July 2007, FDG-PET revealed multiple subcutaneous metastases, and weekly PTX therapy was resumed on the basis of the results about the sensitivity of axillary lymph nodes to anti-cancer agents. The skin metastases diminished in response to this therapy. In October 2007, however, CT revealed multiple subcutaneous metastases and small metastases within the lung. The patient died in January 2008.

The patient's treatment regimen from January 2002 to October 2007 is given in table 1 .

\section{Discussion}

Duodenal cancer is a rare cancer which accounts for only $0.3 \%$ of all gastrointestinal cancers [7]. However, among cancers affecting the small bowel, duodenal cancer is reported to constitute about $50 \%$ of all cases [1]. Reports on this cancer have recently been increasing following improvement in the diagnostic capability thanks to development of small bowel capsule endoscopes and double balloon endoscopes. Attempts of relatively noninvasive treatment have been reported on early-stage duodenal cancer [8]. For advanced duodenal cancer, pancreatoduodenectomy is a standard operative procedure, but this procedure is applicable to about $40 \%$ of all cases, with the postoperative 5 -year survival rate being about $50 \%$ [2]. The 2-year survival rate for cases of inoperable duodenal cancer is reported to be $<20 \%$, with the 5 -year survival rate being $0 \%$ and median survival time being 7 months $[9,10]$. Chemotherapy has been viewed as little useful as a means of treating inoperative duodenal cancer [11] and no standard therapy for inoperative duodenal cancer has been established. However, patients with inoperative duodenal cancer having survived long after active chemotherapy have recently been reported sporadically, and it is now desirable to establish standard chemotherapy for such cases. Ohkusa et al. reported that a patient with adenocarcinoma of duodenal bulb origin, accompanied by multiple liver metastases, survived for 3 years and 4 months after combined UFT/mitomycin therapy [12]. Witham and Harnett also reported a patient with duodenal cancer with multiple liver metastases who survived for 3 years after chemotherapy with 5-FU [13].

S-1 is a new oral anti-cancer drug comprised of tegafur, 5-chloro-2,4-dihydroxypyridine, and potassium oxonate. This drug was designed to enhance the efficacy of tegafur, a prodrug of fluorouracil, and has been reported to exert high clinical efficacy when used independently or in combination with other drugs for the treatment of gastrointestinal cancers and various other cancers. Katakura et al. reported that treatment with S-1 resulted in survival for 1 year and 7 months in a patient with duodenal adenocarcinoma with liver metastasis [14]. 
In the present case, the primary lesion assumed a form resembling early-stage cancer, but many lymph node metastases were noted, allowing a judgment of inoperable advanced duodenal cancer. Chemotherapy primarily with S-1 resulted in complete response for a while when rated by diagnostic imaging. Later, recurrence and distant metastasis took place, but multidisciplinary treatment resulted in long survival for 6 years and 1 month. This is a valuable case suggesting the usefulness of this therapeutic approach. In view of the fact that duodenal cancer is a relatively rare disease and the possibility that the incidence of this disease may increase in the future, it seems essential to collect additional data from multicenter prospective studies towards the goal of establishing a standard method of treatment for this disease.

\section{Disclosure Statement}

The authors have no conflict of interest.

Table 1. Treatment regimen from January 2002 to October 2007

\begin{tabular}{lll}
\hline Duration & Treatment & Regimen \\
\hline $2002.1-2002.12$ & S-1/CDDP & $\begin{array}{l}\text { S-1 } 80 \mathrm{mg} / \mathrm{m}^{2} / \text { day } 3 \text { weeks of treatment and subsequent 1-week cessation } \\
\text { CDDP } 60 \mathrm{mg} / \mathrm{m}^{2} \text { day } 8\end{array}$ \\
\hline $2003.1-2003.11$ & S-1/CPT-11 & $\begin{array}{l}\text { S-1 } 80 \mathrm{mg} / \mathrm{m}^{2} / \text { day } 3 \text { weeks of treatment and subsequent 1-week cessation } \\
\text { CPT-11 } 60 \mathrm{mg} / \mathrm{m}^{2} \text { day } 8\end{array}$ \\
\hline $2003.12-2005.1$ & S-1 & S-1 $80 \mathrm{mg} / \mathrm{m}^{2} /$ day 3 weeks of treatment and subsequent 1-week cessation \\
\hline $2005.2-2005.8$ & UFT & UFT $300 \mathrm{mg} /$ day daily oral administration \\
\hline $2005.9-2005.11$ & S-1/CPT-11 & $\begin{array}{l}\text { S-1 } 80 \mathrm{mg} / \mathrm{m}^{2} / \text { day } 3 \text { weeks of treatment and subsequent 1-week cessation } \\
\text { CPT-11 } 60 \mathrm{mg} / \mathrm{m}^{2} \text { day } 8\end{array}$ \\
\hline $2005.12-2006.1$ & weekly PTX & PTX $100 \mathrm{mg} / \mathrm{m}^{2}$ day 1, 8, 15 and subsequent 1-week cessation \\
\hline $2006.2-2006.6$ & weekly docetaxel/ & $\begin{array}{l}\text { Docetaxel } 14 \mathrm{mg} / \text { day weekly } \\
\text { Radiation total } 66 \text { Gy }\end{array}$ \\
\hline 2006.7 & gadiotherapy & - \\
\hline $2006.7-2007.1$ & S-1 & S-1 $80 \mathrm{mg} / \mathrm{m}^{2} /$ day 3 weeks of treatment and subsequent 1-week cessation \\
\hline $2007.2,2007.10$ & gamma knife therapy & - \\
\hline $2007.7-2007.10$ & weekly PTX & PTX $100 \mathrm{mg} / \mathrm{m}^{2}$ day 1, 8, 15 and subsequent 1-week cessation \\
\hline The dose of S-1 and UFT is on a tegafur basis. & \\
\hline
\end{tabular}




\begin{tabular}{r|l|l|l}
$\begin{array}{r}\text { Case Reports in } \\
\text { Gastroenterology }\end{array}$ & $\begin{array}{l}\text { Case Rep Gastroenterol 2012;6:111-117 } \\
\text { DOI: 10.1159/000336821 }\end{array}$ & $\begin{array}{l}\text { Published online: } \\
\text { February 18, 2012 }\end{array}$ & $\begin{array}{l}\text { @ 2012 S. Karger AG, Basel } \\
\text { ISSN 1662-0631 } \\
\text { www.karger.com/crg }\end{array}$ \\
\hline
\end{tabular}
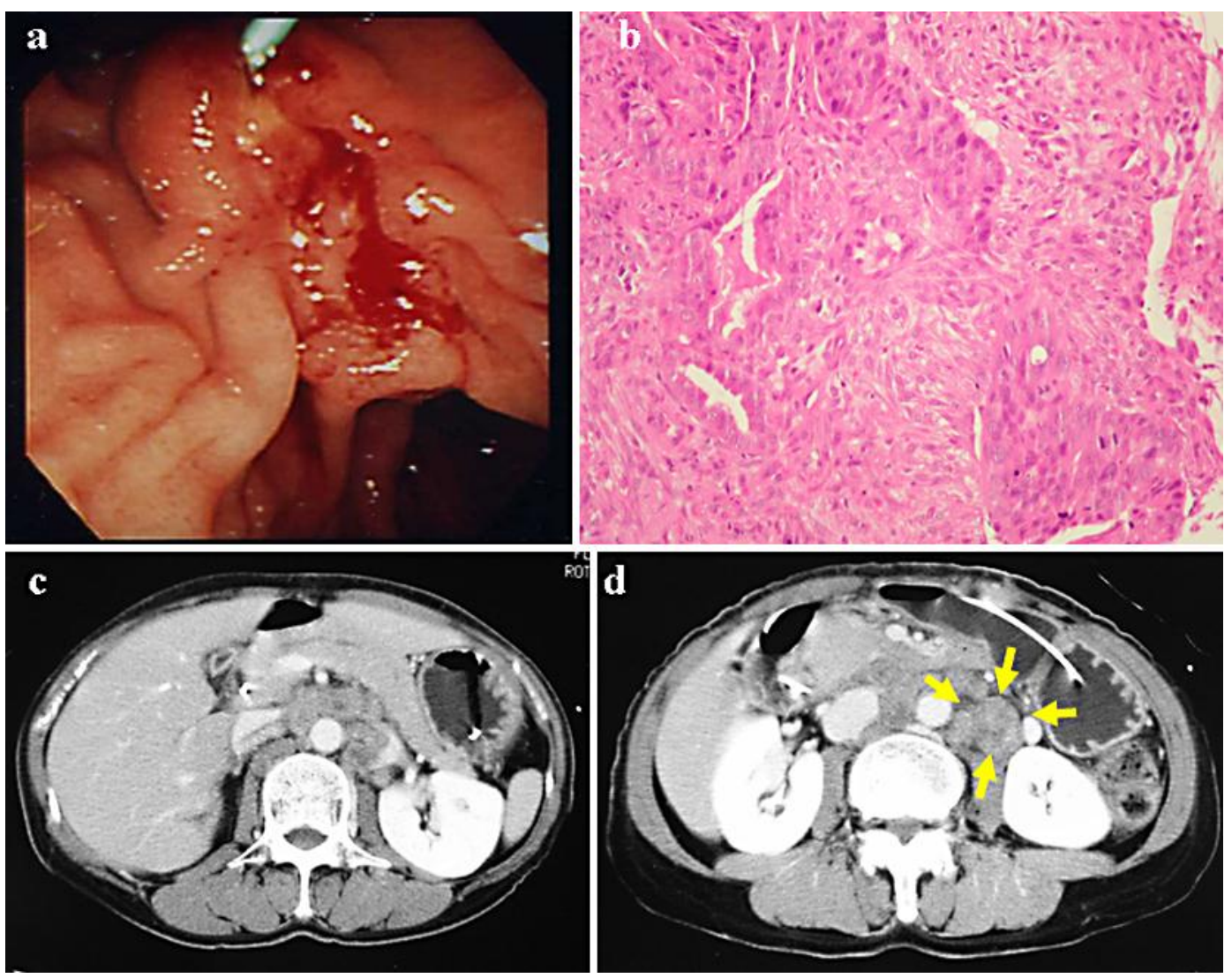

Fig. 1. a Endoscopic finding obtained when endoscopic nasal biliary drainage was switched to endoscopic retrograde biliary drainage at our hospital. A depressed lesion was visible at the distal side of the papillary opening. The lesion was hemorrhagic fragile mucosa. b Biopsy of this site allowed a diagnosis of moderately to well-differentiated adenocarcinoma. c, d Findings from abdominal CT scans upon admission. c CT scans at the level of the duodenal papilla revealed no primary tumor. There was no marked dilatation of the main pancreatic duct or common bile duct. No space-occupying region suggesting metastasis was seen in the liver. No sign of ascites was noted. $\mathbf{d}$ Swelling of the lymph nodes around the aorta, like the ones shown here, was visible at the celiac artery level to the level of the common iliac artery bifurcation. 

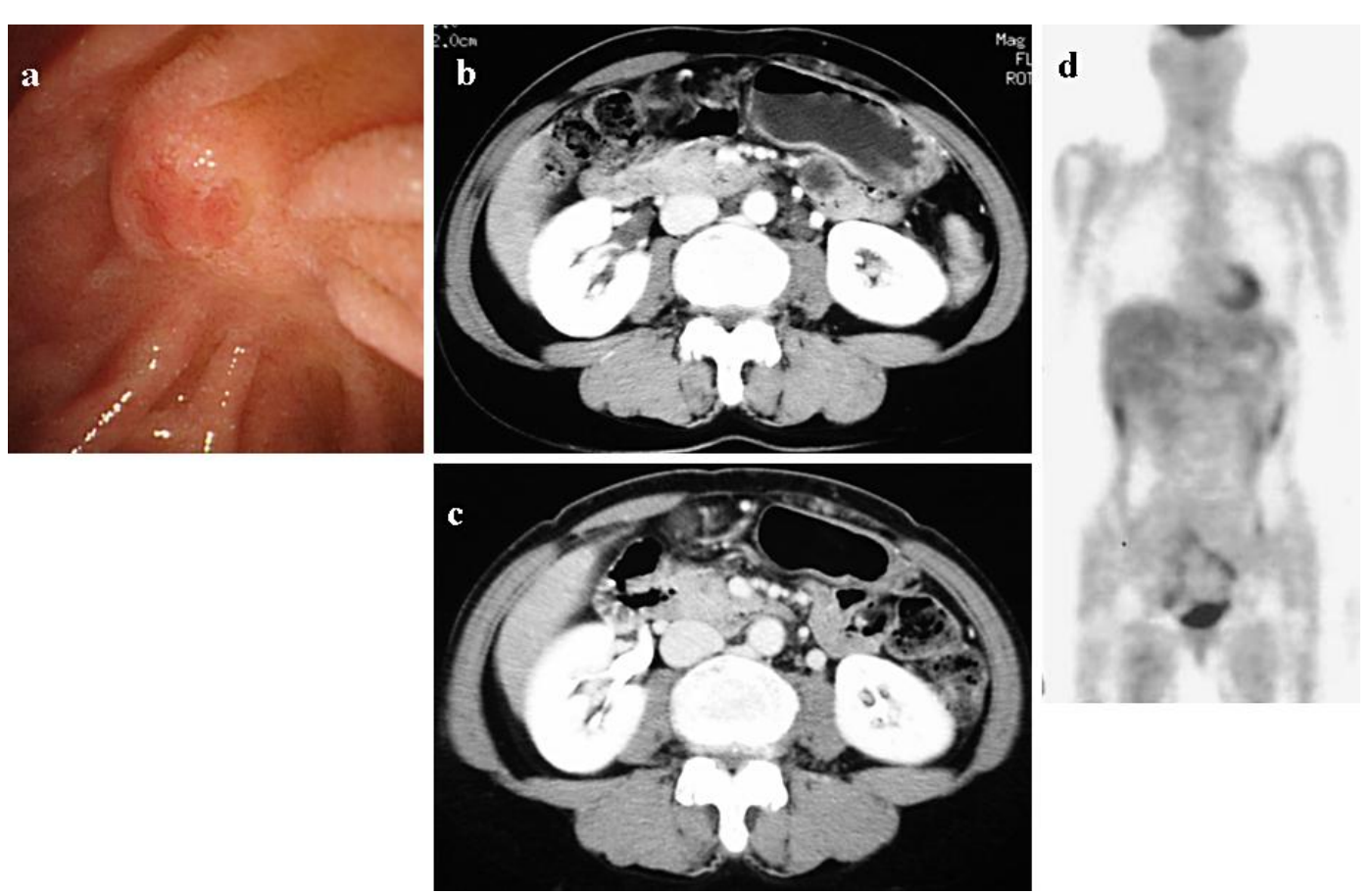

Fig. 2. a, b Endoscopic findings (a) and CT scan (b) after 8 months. The primary lesion disappeared, and lymph node metastases diminished markedly. c, d CT (c) and FDG-PET (d) after 48 months. Swollen lymph nodes were not seen anymore.
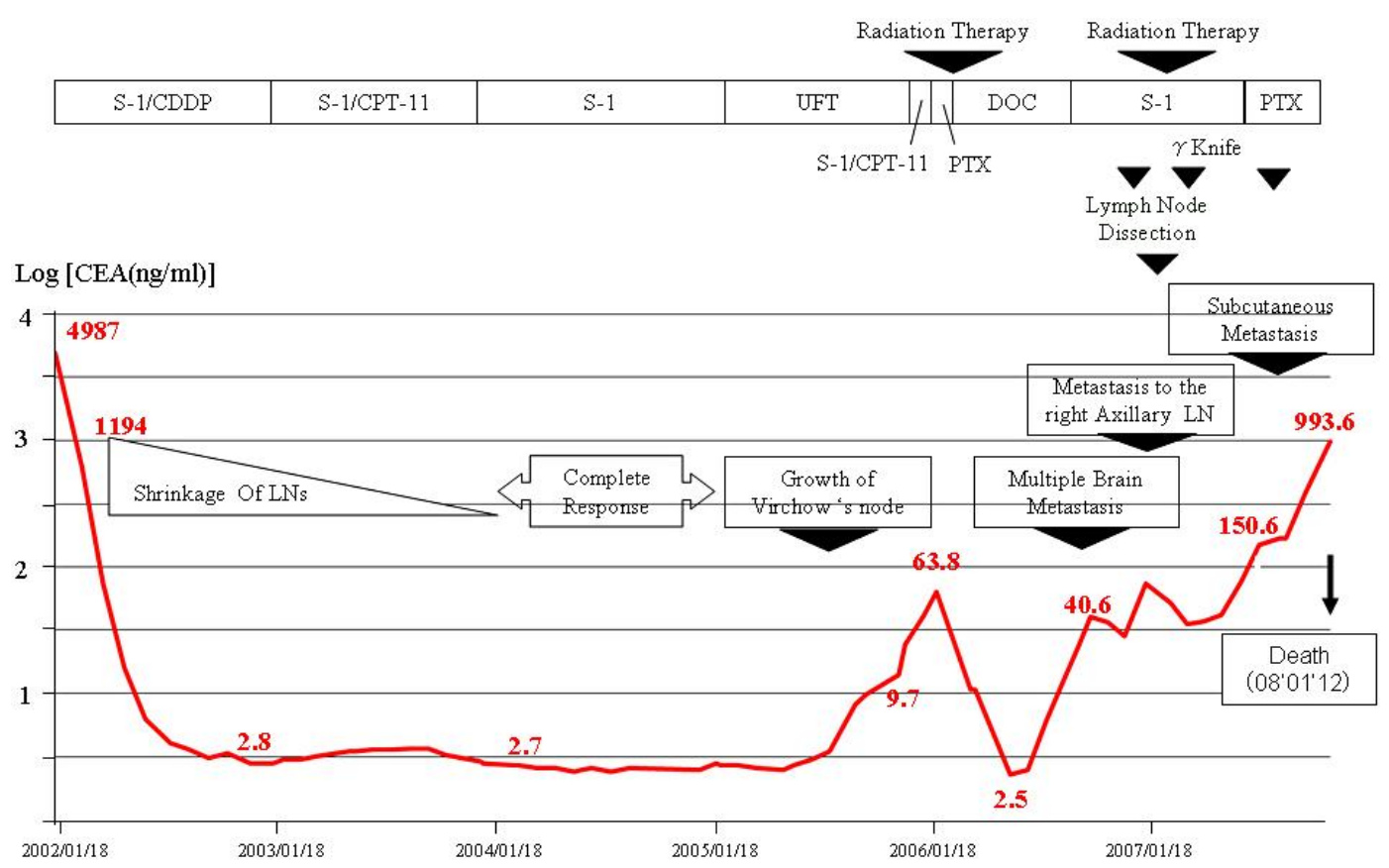

Fig. 3. Time course of CEA and chemotherapy. 


\section{References}

1 Ouriel K, Adams JT: Adenocarcinoma of the small intestine. Am J Surg 1984;147:66-71

2 Barnes G Jr, Romero L, Hess KR, Curley SA: Primary adenocarcinoma of the duodenum: management and survival in 67 patients. Ann Surg Oncol 1994;1:73-78.

-3 Shirasaka T, Shimamato Y, Ohshimo H, Yamagychi M, Kato T, Yonekura K, Fukushima M: Development of a novel form of an oral 5-fluorouracil derivative (S-1) directed to the potentiation of the tumor selective cytotoxicity of 5-fluorouracil by two biochemical modulators. Anticancer Drugs 1996;7:548-557.

-4 Sakata Y, Ohtsu A, Horikoshi N, Sugimachi K, Mitachi Y, Taguchi T: Late phase II study of novel oral fluoropyrimidine anticancer drug S-1 (1 M Tegafur-0.4 M gimestat-1 M otastat potassium) in advanced gastric cancer patients. Eur J Cancer 1998;34:1715-1720.

$>5$ Ohtsu A, Baba H, Sakata Y, Horikoshi N, Sugimachi K, Taguchi T; for the S-1 Cooperative Colorectal Carcinoma Study Group: Phase II study of S-1, a novel oral fluoropyrimidine derivative, in patients with metastatic colorectal carcinoma. Br J Cancer 2000;83:141-145.

-6 Shirao K, Ohtsu A, Takada H, Mitachi Y, Hirakawa K, Horikoshi N, Okamura T, Hirata K, Saitoh S, Isomoto H, Satoh A: Phase II study of oral S-1 for treatment of metastatic colorectal carcinoma. Cancer 2004;100:2355-2361.

7 Moss WM, McCart PM, Juler G, Miller DR: Primary adenocarcinoma of the duodenum. Arch Surg 1974;108:805-807.

8 Ando T, Ueda M, Hongo H, et al: A case of double cancer of the stomach and duodenum resected by endoscopy. Gastroenterol Endosc 1998;40:779-785.

$\checkmark 9$ Scoot-Coombes DM, Williamson RC: Surgical treatment of primary duodenal carcinoma: a personal series. Br J Surg 1994;81:1472-1474.

10 Honiford BT, Iannitti DA, Evans P, Gagner M, Henderson JM: Primary nonampullary/periampullary adenocarcinoma of duodenum. Am Surg 1998;64:1165-1169.

11 Sohn TA, Lillemoe KD, Cameron JL, et al: Adenocarcinoma of the duodenum: factors influencing long-term survival. J Gastrointest Surg 1998;2:79-87.

12 Ohkusa T, Ohtomo K, Yamamoto N, Fujimoto H: Primary adenocarcinoma of duodenal bulb benefitted by chemotherapy. Dig Dis Sci 1991;36:1653-1656.

13 Witham M, Harnett PR: Adenocarcinoma of the duodenum with liver metastases. Complete remission and long-term survival with 5-fluorourascil chemotherapy - a case report. Am J Clin Oncol 1996;19: 305-306.

14 Katakura Y, Suzuki M, Kobayashi M, Nakahara K, Matsumoto N, Itoh F: Remission of primary duodenal adenocarcinoma with liver metastases with S-1 chemotherapy. Dig Dis Sci 2007;52:1121-1124. 